\title{
Role of Endocrine System and Hypothalamic Neuropeptides in Hyperphagia Associated Obesity
}

\author{
Mubashir Abbas*, Abdul Rehman, Zulfia Hussain, Junaid Ali Khan \\ Institute of Physiology and Pharmacology, University of Agriculture, Faisalabad, Pakistan \\ Email address: \\ mubashirabbas92786@gmail.com (M. Abbas), abdulrehman8907@hotmail.com (A. Rehman), zulfia60@gmail.com (Z. Hussain), \\ junaidali.khan@uaf.edu.pk (J. A. Khan) \\ ${ }^{*}$ Corresponding author
}

\section{To cite this article:}

Mubashir Abbas, Abdul Rehman, Zulfia Hussain, Junaid Ali Khan. Role of Endocrine System and Hypothalamic Neuropeptides in Hyperphagia Associated Obesity. Journal of Family Medicine and Health Care. Vol. 7, No. 1, 2021, pp. 14-18.

doi: $10.11648 /$ j.jfmhc.20210701.13

Received: January 3, 2021; Accepted: January 14, 2021; Published: March 10, 2021

\begin{abstract}
Activities occurring in an animal's body are performed and regulated via certain chemicals. These chemical on the basis of multiple factors are divided into various classes. Hormones forma major class of such chemicals. Hormones are integral part of animal's body that are involved in the mediation of a variety of vital functions. Hormonal secretions are precisely regulated in order to mediate relevant function as needed. They are important maintainers of a variety of homeostatic mechanisms including food intake, digestion, absorption and utilization. Like all other parts of animal's body, adipose tissue is also under the influence of chemical messengers. Some of the endocrine messengers are Leptin, Insulin and Ghrelin hormone while neural chemicals include orexigenic hypothalamic neuropeptides (like Neuropeptide Y). While performing normal assigned function these chemical substances strive to maintain a balance between body energy need and energy intake. If concentration or functionality of any of them is disturbed due to certain change for sufficient time period then they fail to perform their duty resulting gradual increase in body mass index. Deficiency or hypersecretion, structural deformity and functional impairment are some of the aspects that contribute towards hormonal abnormalities. Present review is based on a concise discussion about obesogenic role of Leptin, Insulin and Ghrelin hormones and hypothalamic neuropeptides.
\end{abstract}

Keywords: Hyperphagia, Leptin, Insulin, Ghrelin, Adipocity, Endocrine Hormones, Hypothalamic Neuropeptides

\section{Introduction}

A number of hormones that are produced from different locations, act in distinct manner exerting their action on relevant tissues in order to regulate caloric intake. Any indiscretion associated with these hormones may contribute to dietary irregularities [1]. According to a latest study, the primary stimulus behind the act of excessive energy intake is abnormal endocrine signaling to hypothalamus, generating a neural state of constant hunger [2]. Regulation of appetite is an intricate procedure that involves connection between hypothalamus, adipose tissue and organs of digestive system. Following food consumption, a number of hormones are secreted in gastrointestinal tract in response to gastric distension, digestion and absorption in order to signal brain for satiety. Some of the major hormones that are involved in mediating food behaviors via satiety mechanism include insulin, leptin, ghrelin and hypothalamic peptides [3-6].

The core objective to write the article is to present an overview regarding role of some major endocrine hormones; including leptin, insulin and ghrelin, and some hypothalamic neuropeptides like Neuropeptide Y towards undesired surplus caloric intake. Objective of producing this review is to suggest medical researchers and professionals concerned with obesity treatment that they should also consider interaction between over consumption of food, and imbalanced endocrine hormones and neural chemicals like hypothalamic neuropeptides.

\section{Leptin}

Leptin hormone is produced from adipose tissue and amount of production is directly proportional to the level of adiposity. Leptin plays a significant role in the regulation of 
energy homeostasis and body weight control by minimizing desire for food intake and stimulating energy expenditure. Although high serum leptin levels have been observed in obese subjects but failed to perform desired function. Leptin resistance, caused by overconsumption of palatable foods, might be a possible illustration behind this failure that ultimately promotes obesity [7]. Expression of leptin mRNA in stomach was lower in fasted mice, then they were fed with high fat diet for a period of 5 weeks and no significant changes were detected. Higher expression of leptin mRNA was observed when mice were fed with high sucrose diet so it can be concluded from experiment that leptin is mainly associated with carbohydrate metabolism [8].

Leptin transmits information to central nervous system regarding long term energy stores of body and acts indirectly as anorectic signal by inhibiting appetite and appetite stimulants in the hypothalamus [9]. Extreme obesity along with hyperphagia has been observed in experimental leptin deficient mice and the effects were reversed following administration of synthetic leptin [10]. A variety of experimental investigations have provided functional neuroanatomical approaches towards understanding mechanism of action of leptin hormone. Leptin exerts its effects on food consumption associated neuronal circuits and causes reduced perception of food reward and enhanced response to satiety signals. In case of leptin deficiency exaggerated wanting response for desirable foods has been noted that disappeared after treatment with leptin [11]. Leptin receptors are found in different regions including hypothalamic arcuate nucleus [12].

Within the nervous tissue, most remarkable leptin's antiobesity role is played by inhibitory GABAergic neurons. Leptin exerts its action directly on presynaptic GABAergic neurons as an attempt to decrease inhibitory tone to postsynaptic antiobesity POMC neurons. As POMC neurons are associated with prevention of obesity, their enhanced stimulation by decreasing inhibition probably mediates leptin's antiobesity effects to some extent [13]. By the administration of bulk amounts of leptin in normal rats, marked reduction in body fat stores was observed, indicating anti obesity role of leptin hormone [14].

\section{Insulin}

Insulin is an important metabolic hormone that reduces food intake and promotes adiposity [15] and released by pancreatic beta cells in response to hyperglycemia. Insulin plays key role in glucose metabolism and energy storing process in insulin responsive parts of body such as adipocytes and muscular tissue [16]. In case of any impairment, development of some metabolic disorder is highly probable [17]. Production of insulin is directly proportional to the extent of obesity and retains the ability to cross the blood brain barrier in order to reach and act on its receptors in hypothalamus [18].

Glucocorticoids, the end products of hypothalamicpituitary-adrenal (HPA) axis, are the major regulators of insulin and show dual nature by either restraining or stimulating insulin activity on skeletal muscles and adipose tissue [19]. Hyperactivation of HPA axis resulted by stress induces hyperinsulinemia by stimulating process of gluconeogenesis and inhibiting glycolysis [20]. Synergistic effects of insulin and glucocorticoids in stimulating consumption of hyperpalatable foods are demonstrated by various animal studies ultimately driving towards abdominal fat deposition [21, 22]. Insulin acts on nervous system and minimizes neural ability to regulate food ingestion by oppressing brain reward pathway. As a result, one has to consume more food than requirement in order to get the same rewarding effect $[23,24]$.

\section{Ghrelin}

Ghrelin hormone is associated with energy regulations by stimulating hunger when energy status of body goes down. Action of ghrelin on nervous system to regulate body weight, glucose metabolism and obesity was discovered by Mark Heiman and Matthias Tschöp in 2000 [25]. Produced in stress conditions and thought to be involved in stimulation of hyper consumption of foods in order to regulate mode and to minimize deleterious effects associated with stress and anxiety [26]. Primary function of ghrelin hormone is to conserve energy for vital functions in case of low energy availability by triggering fatty acid oxidation and favoring food seeking behavior [27].

Ghrelin monitors metabolic effects in a number of ways including taste sensation, reward seeking behavior and regulation of appetite, gut motility, provoking discharge of growth hormone and glucose metabolism. Prominent role of ghrelin in the development of adiposity is accredited to increased appetite due to over activation of lipogenesis and orexigenic neural hypothalamic pathways [28]. Chronic infusion of ghrelin boosts up the glucose utilization of white and brown adipose tissues. In white adipose tissue, mRNA expression level of a number of fat storage inducing enzymes including lipoprotein lipase, fatty acid synthase, acetyl-CoA carboxylase $a$ and stearoyl-CoA desaturase-1 was significantly higher. Moreover, expression level of fat oxidation reducers as carnitine palmitoyl transferase-1a was lower. In brown adipose tissue, ghrelin infusion resulted in minimized expression of mitochondrial uncoupling proteins 1 and 3 that are related with thermogenesis [29]. In addition to potential orexigenic properties, ghrelin is also involved in the regulation of reward based hedonic eating behaviors [30].

Dopamine is a key mediator of ghrelin activity in neural reward circuit due to its involvement in reward related behaviors [31]. Ghrelin stimulates individuals to eat even when they are not hungry. Stress and ghrelin secretion are directly linked with each other in such a way that over production of ghrelin induces stress like response while on the other hand stress stimulates ghrelin secretion [32-34]. Initiation of meal, short term feeding behavior and long term increase in body weight by enhancing appetite and diminishing fat utilization, is suggested to be caused by 
ghrelin [35].

Ghrelin encourages a state of positive energy balance and body weight gain by provoking higher energy consumption and lower energy utilization [36]. In addition, it stimulates gastric emptying, nutrient storage and release of growth hormone. Based on available evidences it has been proposed that ghrelin based compounds may be an important therapeutic strategy in treating malnutrition caused by some sub-acute and chronic disorders [37]. Circulating free fatty acids suppress ghrelin production [38] while glucocorticoids stimulate it [26]. Contrary to these investigations, some studies have claimed suppressed expression of ghrelin by all types of palatable diets but still it fails to restrain the hyperphagia associated with these diets indicating an impaired ghrelin sensitivity [8]. Pleiotropic nature of ghrelin makes it much difficult to be used as selective treatment in a range of pharmacological interventions [27].

\section{Hypothalamic Neuropeptides}

Extent of food intake and energy expenditure is mainly controlled by central nervous system via tight management between two major neuronal populations; proopiomelanocortin (POMC) and the neuropeptide Y (NPY) neurons, both are found in arcuate nucleus. Former is involved in the suppression of appetite (anorexigenic) while later in the stimulation (orexigenic) [39]. A number of other neuropeptides are also involved in the regulatory activities including agouti-related peptide (AgRP), melanocortin receptors and corticotropin-releasing factor (CRF) [40]. A well coordinated interaction between these circuits is mandatory to maintain proper energy balance, any alteration may lead to overeating and obesity [41].

Hypothalamus is a principle relay center in regulation of feed intake [42] by producing a variety of orectic and anorectic neuropeptides [43] in response to signals from brain, peripheral circulation and digestive organs [44]. NPY is considered as one of the powerful orexigenic peptides found in nervous system that is linked with hyperphagia as it effectively stimulates desire for food ingestion and reduces satiety responses [45]. Higher expression of POMC mRNA has been noted following a high fat diet for several days showing an inclination towards overconsumption of hyperpalatable foods by triggering neural alterations [46]. Moreover, increased desire for carbohydrates was observed [47] that was contained to hypothalamus [48] after an intracerebroventricular injection of NPY [49].

\section{Conclusion}

One of the major causes of obesity is over the requirement ingestion of food consistently. A number of factors are responsible for this unnecessary hyper-consumption; one of them is associated with alteredlevels of some hormonal and neural chemicals. Laptin, Insulin, Ghrelin and hypothalamic neuropeptides are a few major regulators of body fat content. Leptin normally keeps a check on stored fatty material by stimulating lipolysis but fails upon encountering resistance. Insulin induces adiposity in addition to carbohydrate metabolism, thus the state of hyperinsulemia triggers higher adipose tissue buildup. Contrary to common view that insulin diminishes desire for food, certain investigations claim stimulatory effect of insulin for food intake. Ghrelin is released in hypoglycemic state and induces hunger. It acts as obesogenic substance by inducing higher caloric intake and neural lipogenic pathway. In addition, higher concentration of orexigenic hypothalamic neuropeptides like Neuropeptide Y (NPY) induces hyperphagia through various neural alterations that gradually direct towards overweight and obesity.

\section{Conflict of Interest Statement}

The authors declare that they have no competing interests.

\section{Ethical Statement}

This article does not contain any studies with human participants or animals performed by any of the authors.

\section{References}

[1] Aller EEJG, Abete I, Astrup A, et al., 2011. Starches, Sugars and Obesity. Nutrients 3: 341-369.

[2] Davies JR, Humby T, Dwyer DM, et al., 2015. Calorie seeking, but not hedonic response, contributes to hyperphagia in a mouse model for Prader-Willi syndrome. Eur J Neurosci 42: 2105-2113.

[3] Benelam B, 2009. Satiation, satiety and their effects on eating behaviour. Nutr Bull 34: 126-173.

[4] Delzenne N, Blundell J, Brouns F, et al., 2010. Gastrointestinal targets of appetite regulation in humans. Obes Rev 11: 234-250.

[5] Karra E and Batterham RL, 2010. The role of gut hormones in the regulation of body weight and energy homeostasis. Mol Cell Endocrinol 316: 120-128.

[6] Neary MT and Batterham RL, 2009. Gut hormones: Implications for the treatment of obesity. PharmacolTher 124: 44-56.

[7] Scarpace PJ and Zhang Y, 2009. Leptin resistance: a prediposing factor for diet-induced obesity. Am J PhysiolRegulIntegr Comp Physiol 296: R493-R500.

[8] Lindqvist A, de la Cour CD, Stegmark A, et al., 2005. Overeating of palatable food is associated with blunted leptin and ghrelin responses. RegulPept 130: 123-132.

[9] Williams KW, Scott MM and Elmquist JK, 2009. From observation to experimentation: leptin action in the mediobasal hypothalamus. Am J ClinNutr 89: 985S-990S.

[10] Pelleymounter M, Cullen M, Baker M, et al., 1995. Effects of the obese gene product on body weight regulation in ob/ob mice. Science 269: 540-543. 
[11] Farooqi IS, Bullmore E, Keogh J, et al., 2007. Leptin Regulates Striatal Regions and Human Eating Behavior. Science 317: 1355-1355.

[12] Myers MG, Cowley MA and Münzberg H, 2008. Mechanisms of Leptin Action and Leptin Resistance. Annu Rev Physiol 70: 537-556.

[13] Vong L, Ye C, Yang Z, et al., 2011. Leptin Action on GABAergic Neurons Prevents Obesity and Reduces Inhibitory Tone to POMC Neurons. Neuron 71: 142-154.

[14] Chen G, Koyama K, Yuan X, et al., 1996. Disappearance of body fat in normal rats induced by adenovirus-mediated leptin gene therapy. Proc Natl AcadSci 93: 14795-14799.

[15] la Fleur SE, Akana SF, Manalo SL, et al., 2004. Interaction between Corticosterone and Insulin in Obesity: Regulation of Lard Intake and Fat Stores. Endocrinology 145: 2174-2185.

[16] Baskin DG, FiglewiczLattemann D, Seeley RJ, et al., 1999. Insulin and leptin: dual adiposity signals to the brain for the regulation of food intake and body weight. Brain Res 848: 114-123.

[17] Loh K, Zhang L, Brandon A, et al., 2017. Insulin controls food intake and energy balance via NPY neurons. MolMetab 6 : 574-584.

[18] Schwartz MW, Figlewicz DP, Baskin DG, et al., 1992. Insulin in the Brain: A Hormonal Regulator of Energy Balance. 13: 28 .

[19] Chrousos G, 2000. The role of stress and the hypothalamicpituitary-adrenal axis in the pathogenesis of the metabolic syndrome: neuro-endocrine and target tissue-related causes. Int J Obes 24: S50-S55.

[20] Pasquali R, Vicennati V, Cacciari M, et al., 2006. The Hypothalamic-Pituitary-Adrenal Axis Activity in Obesity and the Metabolic Syndrome. Ann N Y AcadSci 1083: 111-128.

[21] Dallman MF, la Fleur SE, Pecoraro NC, et al., 2004. Minireview: Glucocorticoids-Food Intake, Abdominal Obesity, and Wealthy Nations in 2004. Endocrinology 145: 2633-2638.

[22] Warne JP, 2009. Shaping the stress response: Interplay of palatable food choices, glucocorticoids, insulin and abdominal obesity. Mol Cell Endocrinol 300: 137-146.

[23] Turner A, Veysey M, Keely S, et al., 2018. Interactions between Bitter Taste, Diet and Dysbiosis: Consequences for Appetite and Obesity. Nutrients 10: 1336.

[24] Warne JP, Akana SF, Ginsberg AB, et al., 2009. Disengaging insulin from corticosterone: roles of each on energy intake and disposition. Am J Physiol-RegulIntegr Comp Physiol 296: R1366-R1375.

[25] Tschöp M, Smiley DL and Heiman ML, 2000. Ghrelin induces adiposity in rodents. Nature 407: 908-913.

[26] Chuang J-C and Zigman JM, 2010. Ghrelin's Roles in Stress, Mood, and Anxiety Regulation. Int J Pept 2010: 1-5.

[27] Pinkney J, 2014. The role of ghrelin in metabolic regulation: Curr Opin Clin Nutr Metab Care 17: 497-502.

[28] Poher A-L, Tschöp MH and Müller TD, 2018. Ghrelin regulation of glucose metabolism. Peptides 100: 236-242.
[29] Theander-Carrillo C, 2006. Ghrelin action in the brain controls adipocyte metabolism. J Clin Invest 116: 1983-1993.

[30] Perelló M and Zigman JM, 2012. The Role of Ghrelin in Reward-Based Eating. Biol Psychiatry 72: 347-353.

[31] Palmiter RD, 2007. Is dopamine a physiologically relevant mediator of feeding behavior? Trends Neurosci 30: 375-381.

[32] Carlini VP, Monzón ME, Varas MM, et al., 2002. Ghrelin increases anxiety-like behavior and memory retention in rats. BiochemBiophys Res Commun 299: 739-743.

[33] Kawakami A, Kawakami A, Okada N, et al., 2008. Leptin inhibits and ghrelin augments hypothalamic noradrenaline release after stress: Research Report. Stress 11: 363-369.

[34] Rouach V, Bloch M, Rosenberg N, et al., 2007. The acute ghrelin response to a psychological stress challenge does not predict the post-stress urge to eat. Psych neuroendocrinology 32: 693-702.

[35] Cummings DE, 2006. Ghrelin and the short- and long-term regulation of appetite and body weight. PhysiolBehav 89: 7184.

[36] Asakawa A, Inui A, Kaga O, et al., 2001. Ghrelin is an appetite-stimulatory signal from stomach with structural resemblance to motilin. Gastroenterology 120: 337-345.

[37] Castañeda TR, Tong J, Datta R, et al., 2010. Ghrelin in the regulation of body weight and metabolism. Front Neuroendocrinol 31: 44-60.

[38] Gormsen LC, Gjedsted J, Gjedde S, et al., 2006. Free fatty acids decrease circulating ghrelin concentrations in humans. Eur J Endocrinol 154: 667-673.

[39] Boswell T, Li Q and Takeuchi S, 2002. Neurons expressing neuropeptide $\mathrm{Y}$ mRNA in the infundibular hypothalamus of Japanese quail are activated by fasting and co-express agoutirelated protein mRNA. Mol Brain Res 100 (1-2): 31-42.

[40] Maniam J and Morris MJ, 2012. The link between stress and feeding behaviour. Neuropharmacology 63: 97-110.

[41] Sohn J-W, 2015. Network of hypothalamic neurons that control appetite. BMB Rep 48: 229-233.

[42] Schwartz MW, Woods SC, Porte D, et al., 2000. Central nervous system control of food intake. Nature 404: 661-671.

[43] Arora S and Anubhuti, 2006. Role of neuropeptides in appetite regulation and obesity - A review. Neuropeptides 40: 375401.

[44] Richards M, 2003. Genetic regulation of feed intake and energy balance in poultry. Poult Sci 82: 907-916.

[45] Beck B, 2006. Neuropeptide Y in normal eating and in genetic and dietary-induced obesity. Philos Trans R Soc B BiolSci 361: 1159-1185.

[46] Mizushige T, Kawai T, Matsumura S, et al., 2006. POMC and orexin mRNA expressions induced by anticipation of a cornoil emulsion feeding are maintained at the high levels until oil ingestion. Biomed Res 27: 227-232.

[47] Stanley BG, Daniel DR, Chin AS, et al., 1985. Paraventricular nucleus injections of peptide YY and neuropeptide $\mathrm{Y}$ preferentially enhance carbohydrate ingestion. Peptides 6: $1205-1211$. 
[48] Stanley BG, Chin AS and Leibowitz SF, 1985. Feeding and drinking elicited by central injection of neuropeptide Y: Evidence for a hypothalamic site (s) of action. Brain Res Bull 14: 521-524.
[49] Clark JT, Kalra PS, Crowley WR, et al., 1984. Neuropeptide y and human pancreatic polypeptide stimulate feeding behavior in rats. Endocrinology 115: 427-429. 